\title{
Calculating the efficiency indicators in implementing purchase processes
}

\author{
Vanessa Prajová ${ }^{1, *}$, Mária Homokyová ${ }^{1}$, and Martina Horvátová ${ }^{1}$ \\ ${ }^{1}$ Slovak University of Technology, Faculty of Materials Science and Technology, Institute of \\ Industrial Engineering and Management, J. Bottu 25, 91724 Trnava, Slovakia
}

\begin{abstract}
The aim of the paper is to create a theoretical and analytical basis for the topic of calculating the efficiency of the implementation of the purchasing process. This topic is the main subject of research and as the subject of research there are data on the cost of deployment and operation of Enterprise Resource Planning of the world's leading suppliers. The contribution is mainly in processing theoretical solutions of the problem based on study of available materials and designing various types of metrics for execution of purchasing processes.
\end{abstract}

\section{Why and how to define an ERP system}

From the very beginning of its existence and the professional involvement of its members and partners, the Information Systems Research Center has been working to define the terminology in business information systems as favorable as possible. The basis for defining the ERP and its characteristics is the knowledge of the global ERP research conducted by Deloitte Consulting and published in its ERP's Second Wave - A Global Research Reports 2000 report. The final form of the ERP definition was formulated as follows [1]:

"We define the ERP category information system as an effective tool that is capable of covering the planning and management of major internal business processes (resources and their transformation into outputs), at all levels, from operational to strategic."

The most important features of the ERP system include [1, 2]:

- automation and integration of major business processes;

- data sharing, procedures, and standardization across the enterprise;

- creating and making available real-time information;

- ability to process historical data;

- a holistic approach to promoting ERP concepts.

The main requirements for ERP systems include [1, 2]:

- implementing measurable benefits in reducing the entire cost structure resulting from inefficient corporate governance;

* Corresponding author: vanessa.prajova@stuba.sk 
- realization of immeasurable benefits in the field of business process management and availability of information in the real world.

Every business should be aware of the importance of ERP. Define the benefits of using ERP for your business [3]:

- Increasing productivity - The basis of ERP is the unification of all business processes into a simple application, which makes the whole enterprise more efficient. Knowledge of needs of customers, production is faster, the ability to manage relationships with suppliers, track the entire purchasing process to the "best fit" for the customer.

- Integration of all processes into one whole - Linking all the information in the business is no longer a problem. Failure to keep a large number of business running databases separate because the system will allow you to access them at any time.

- Quality analysis and reporting - Easy reporting, various statistics, predictions and especially keep up to date on what is happening in the business.

- Fast communication between business departments - Collaboration between departments is improving because all information is stored, shared and accessible in one system.

- An effective solution for everyone - As all processes are integrated within ERP, repetitive processes are eliminated in the enterprise. The number of manual activities is reduced, processes of all departments in the company are accelerated and simplified.

- $\quad$ Saves costs - Administrative and operational costs are reduced. Effective management of all operations, make faster decisions, and avoid potential failures, delays, and overall money savings.

- Customer Relationship Management - With ERP, is a better option know your customers and provide them with better products and services than their competitors. With effective communication, faster access to customer information, will be chosen more effectively select targeting strategies. Overall, ERP enhances customer relationship management (CRM) and marketing.

- Flexible customization - High configurability, flexibility, customization to ensure that there is no need to purchase a new system for changes in business management or business growth. ERP adapts flexibly to business.

\section{Process performance measurement}

Process performance measurement refers to activities that are intended to provide objective and accurate information about the progress of individual processes so that they can be managed by their processors to meet all process requirements. Without processing data from process performance measurement results, objective process control is not possible. The relationship between quality, productivity and performance is also related to the issue of process performance measurement. The quality of a product reflects its level of ability to meet customer requirements and requirements imposed by legislation. Productivity is linked to the need to use resources and inputs efficiently to carry out the process. The better the use of material, human and information resources, the greater the productivity, which also determines the achievement of results, [2]. If these results are directed towards meeting customer requirements and legislative requirements, quality and productivity are factors that directly and significantly affect performance. Most productivity problems are associated with insufficient quality, and efforts to increase productivity should lead to the resolution of process-related disagreements. At the same time, efforts to improve 
performance are efforts to address productivity and quality improvement issues. Process and organization performance is a function of quality and productivity. The organization should use appropriate methods for monitoring and measuring processes that demonstrate their ability to achieve planned results. If the planned results are not achieved, corrective action and corrective action should be taken as necessary to ensure product compliance, [4].

\section{Universal process performance indicators}

If the nature of many indicators is related to the uniqueness of processes, there are some indicators that are universal in nature and can be used in a variety of measurements.

Universal process performance metrics are typically associated with the following categories [5]:

- the time when we calculate the running time of the process

- quality, reported by the range of non-conformities in $\%$, in ppm,

- flexibility, ability to respond to changes in the process,

- costs, e.g. total process costs,

- $\quad$ environmental impact, e.g. noise level.

\section{Indicators of non-production process performance measurement}

Non-production processes - all other processes that are within the product implementation in organizations [5]:

- $\quad$ processes before production (e.g. marketing research, development, etc.);

- processes in progress (e.g. tool repair, testing, maintenance, etc.);

- $\quad$ processes after production (delivery, service, etc.).

Examples of indicators for measuring non-production process performance [5]:

- indicators for measuring the performance of product design and development processes;

- indicators for measuring the performance of the maintenance process;

- indicators for measuring the performance of the purchase process;

- indicators for measuring the performance of the after-sales service process, etc.

\section{Process performance measurement procedures}

Processes for measuring non-production process performance include [5]:

- measurement of process performance by means of deviations;

- measuring process performance using a performance index;

- measuring process performance using Sigma capability.

\section{A competitive advantage as a core metrics for organizational performance}

The current competitive advantage of the organization is related to competencies, its quality, productivity, and flexibility capabilities, as they are displayed in products offered to the market and identified by customers as valuable. These three generic characteristics are the core metrics of the organization's performance, closely related to each other, in synergy with each other [6]:

- Quality means satisfying customer needs.

- Productivity generally means using all resources and performing every job efficiently and efficiently. 
- Flexibility, flexibility is the ability to adapt quickly to changes in the market and individual customer requirements. The issue of flexibility growth is associated with a reduction in cycle times.

\section{Metrics for ERP Vendor Selection}

- $\quad$ offered IT functionality (ERP, CRM, SCM, BI, etc.);

- user requirements;

- application requirements for client hardware and software;

- $\quad$ provider pricing policy;

- testing applications and their conditions;

- customization options at customer's request;

- application localization options;

- application deployment areas;

- number of implementations;

- guaranteed metrics;

- $\quad$ integrity of individual IT modules with client applications.[7]

\section{Traditional financial metrics}

- cash flow indicators;

- $\quad$ work productivity;

- $\quad$ profit per customer;

- $\quad$ profit per employee;

- $\quad$ net profit;

- company turnover, turnover per customer;

- stock levels;

- costs;

- return on capital.[8]

\section{Using metrics}

- identifying key processes in terms of business efficiency and competitiveness;

- appointment of process owners;

- identifying key activities of these processes;

- $\quad$ setting process priorities;

- prioritize key activities within individual processes;

- convert area weights and key activities to one absolute value;

- defining metrics target;

- introducing a metric system into the systematic involvement of process owners and their representatives;

- assessment of existing soft metrics;

- choosing key top priority activities;

- $\quad$ assign hard metrics to key soft metrics;

- $\quad$ assessing existing hard metrics and determining their target values;

- assessing the costs needed to achieve the IT support target and budgeting for IS / IT innovation;

- $\quad$ subsequent measurements and evaluations.[7] 


\section{Example of calculation of benefits in reducing non-contractual expenses}

\section{Description}

Non-contractual expenditure refers to purchases made outside the agreed price calculation as a one-time, spot purchase. Often, these purchases are made unexpectedly without thinking about the right supplier, high prices, item standardization, and approved terms and conditions. Often these purchases are made to general expense accounts or through shopping cards. In some cases, a non-contractual expense may also be caused by an incumbent supplier if it does not comply with standards such as price, quality, and delivery, [9].

\section{Economic importance}

Purchasing organizations negotiate aggressively with their suppliers to determine the best price, contract terms and other benefits that benefit the business. Many of these negotiated contracts require specific annual purchasing volumes. If purchases are made outside these terms, the business is at risk of losing the agreed benefit. Examples are e.g. lost contracted discounts, violations of volume prices or purchase commitments. These deliveries may be less controlled and corporate controls negate procedures specifically related to expenditure control. Furthermore, the survey showed that purchases made outside the agreed contracts can cost the company $27 \%$ of the purchase price, [9].

\section{Realization of benefits}

The regulation of non-contractual expenditures requires tools and processes that strengthen business rules and force the purchase of office supplies, computer accessories, economic items, and other indirect purchases through established, authorized purchasing processes. Fines (such as declined payments) must be applied to purchases made outside these channels. By promoting purchases through approved suppliers, the company ensures that they receive a negotiated contract price for certain goods against a higher retail price. Compliance with purchasing procedures can be ensured by using technology to automate the requisition process, by submitting only those items that have been pre-approved and pre-negotiated, [9].

To determine the percentage of savings, the studies are based on: A joint survey between AMR and the Institute of Supply Chain Management. The study shows that non-contractual expenditure is responsible for up to $30 \%$ of indirect expenditure and that such expenditure costs the company up to $27 \%$ on lost discounts.

AMETEK consolidated non-contractual expenses and cut costs across the company by $14 \%$, saving nearly 600,000 USD, [10].

Xerox predicts a stable savings rate of 10 mil. USD per year, increasing their purchases under approved contracts from $30 \%$ to $80 \%$, [11].

Aberdeen study shows that typical benefits include 55\% improved screening, 20-35\% lower administrative costs, $50 \%$ savings in cycle time, [12].

\section{Conclusions}

The success factors for deploying metrics include the existence of an enterprise and information strategy, the knowledge of the essential characteristics of metrics, the assessment based on metrics, the knowledge and practice of working with metrics, the unification of existing information systems, and the streamlining of all processes into a new 
unified system. Other factors for the success of ERP include simplifying the workload of output data for management, high adaptability when changing business processes, and introducing a solution that enhances the company's reputation and is capable of long-term development and support. At the same time, it is necessary to reduce the number of applications used, to switch to one integrated solution, to avoid duplication of data entry into the system, to ensure on-line data processing and time-efficient work in the company. The benefits of using the calculation of efficiency indicators in the implementation of purchasing processes are mapping the current situation of calculating efficiency and benefits in the deployment of ERP systems, identifying factors that influence purchasing efficiency and performance, finding return coefficients for individual indicators, and the ability to calculate the return on implementation of purchasing processes within the ERP implementation.

Acknowledgement: The paper has been written as a partial outcome of the project KEGA No.015 STU-4/2018: "Specialised laboratory suppoted by multimedia textbook for subject: „Production systems design and operation" for STU Bratislava.

\section{References}

1. P. Sodomka, Information systems in business practice (Computer Press, a.s. Brno, 2006)

2. M. Kučera et al., Business information systems (Slovenská pol’nohospodárska univerzita v Nitre, 2017)

3. https://implemento.sk/preco-je-erp-system-dolezity-pre-podniky/

4. J. Basl, Enterprise information systems - an enterprise in the information society (Grada Publishing, Praha, 2002)

5. http://www.kvalitaprodukcie.info/meranie-vykonnosti-procesov/

6. I. Vrana at al., Principles and procedures for the implementation of enterprise information systems (Grada Publishing, Praha, 2005)

7. M. Kováč, Transfer inovácií 13 (2009)

8. P. Učen et al., Metrics in Informatics - how to objectively find out the benefits of an information system (Grada Publishing, Praha, 2011)

9. V. Šurka, Proposal of methodology for calculation of efficiency indicators in implementation of purchasing processes, Dissertation thesis (2019)

10. http://www.oracle.com/pls/cis/Profiles.print_html?p_profile_id=3524

11. http://www.oracle.com/pls/cis/Profiles.print_html?p_profile_id=3361

12. http://globalxchange.oraclecorp.com/pls/gxchange/docs/page/rootcorner/sales_kit_repo sitory/products/applications/advancedprocurement/spend $\% 20$ compliance $\% 20$ magagem ent.pdf 